\title{
A Clinical Study on Prescribing Patterns of NSAIDs and Assessment of Drug Interactions
}

\section{RaviTeja Pappala ${ }^{1 *}$, Beula Sandiri ${ }^{1}$, Laxmi Priya Peddi' ${ }^{1}$ RajKishore Pappala $^{2}$, MRPL Pravallika ${ }^{2}$ and G Prashanthi ${ }^{3}$}

${ }^{1}$ Pharm D, KLR Pharmacy College, Kakatiya University, Telangana, India

${ }^{2}$ Pharm D, Shri Vishnu College of Pharmacy, Andhra University, India

${ }^{3}$ Pharm D, Sri Indu Institute of Pharmacy, JNTU University, Telangana, India
Received: April 10, 2020

Published: April 29, 2020

(C) All rights are reserved by RaviTeja

Pappala., et al.

*Corresponding Author: RaviTeja Pappala, Pharm D, KLR Pharmacy College, Kakatiya

University, Telangana, India.

DOI: $10.31080 /$ ASPS.2020.04.0537

\begin{abstract}
Aim: The aim of this study is to determine the prescribing patterns of Non-steroidal anti-inflammatory drugs in different inpatient departments and assessing probable drug interactions.

Methodology: It is a prospective observational study for over a period of 6 months, data was collected from the case sheets of patients those are prescribed with the variety of NSAID's.

Results: Our study reported 260 subjects of which 133 (51.15\%) and 127 (48.85\%) were males and females respectively. Majority of the patients were admitted to the Female Medical Ward (FMW) 59 (46.46). The commonest clinical indications for prescribing NSAIDs was Lower backache (LBA) 36 (13.85\%) followed by others. Most frequently prescribed NSAID was diclofenac 157 (42.32\%) followed by aceclofenac $76(20.48 \%)$, paracetamol 60 (16.17\%), etc. The drug-drug interactions identified was categorized into three different sets, major (10.46\%) moderate (74.06\%) and minor (15.48\%).

Conclusion: Based on the obtained results we conclude that the monotherapy with single NSAID was preferred mode of therapy via parenteral or oral therapy and GPA's should be co-prescribed for prevention from complications and there is a need to implement continuous monitoring of the drug interactions is to be prioritized to prevent adverse drug reactions which are major concern of drug interaction effects with the NSAID's.
\end{abstract}

Keywords: NSAID; DDI; GPA; FMW; LBA

\section{Introduction}

Non-Steroidal anti-inflammatory drugs (NSAIDs) are most commonly and widely used category of drugs for management of pain and inflammation in many clinical conditions [1]. NSAIDs are the class of drugs with analgesic, anti- pyretic and anti- inflammatory effects [2]. Different types of NSAIDs are available over the counter in many formulations including tablets, injections and topicals etc. (there are now more than 50 different NSAIDs on the global market). They are widely misused and often taken without prescription for some types of minor aches and pains that are not necessarily indicated for NSAIDs [3]. NSAIDs provide symptomatic relief from pain and swelling in many disease conditions such as occur in rheumatoid arthritis, osteoarthritis, cervical spondylosis and also in some acute inflammatory conditions such as sports injuries, fractures, sprains, acute arthritic pains and other soft tissue injuries. They also provide relief from post-operative, dental and menstrual pain, headaches and migraine [4]. Drug interactions occur when one drug alters the pharmacological effect of another drug. The pharmacological effect of one or both drugs may be increased or decreased, or a new and unanticipated adverse effect may be produced. Drug interactions may result from pharmacokinetic interactions (absorption, distribution, metabolism, and excretion) or from interactions at drug receptors [5].
NSAID-related pharmacodynamic interactions may be considerably more important in the clinical context, and prescriber ignorance is likely to be a major determinant of many adverse drug interactions [6].

\section{Literature Survey}

Anita P Antappan., et al. have done a prospective observational study on current prescription pattern of NSAIDs and the prevalence of NSAID-induced GI risk factors in orthopedic inpatient over a period of 6 months included 105 subjects taking NSAIDs for more than a week. A self-administered questionnaire was completed by each patient. A simplified risk scoring scale (the Standardized Calculator of Risk for Events; SCORE) was used to measure patients risk for GI complications in conclusion, physician's considerate prescription of NSAIDs with well understanding of each patients GI risk factors is strongly encouraged to prevent serious GI complications [7].

Humaira Farheen., et al. has done a prospective study in 306 subjects to assess the NSAIDs prescription pattern in patients with MS (musculoskeletal) pain in OPD at Owaisi hospital in January 2014 to August 2015. Data collected was analysed by frequency and percentage. Overall frequency of NSAIDS in prescription in 
this study was $96 \%$. Diclofenac (70\%) was the commonest NSAIDS prescribed and finally overall the prescription patterns of NSAIDS was accordance with standard guidelines, as suggested by the fact that the DU90\%, Segment was constituted by only few drugs [8].

S Kumar has done a 6 months prospective study in 400 patients using NSAIDs with secondary objectives of assessment of co-prescription with gastro-protective agents, the nature and severity of ADR and drug-drug interactions with an intention to prevent the inappropriate use of NSAIDs. The major complaint was arthritic pain $(25.5 \%)$. Most of the patients (77\%) were prescribed single NSAID. Combination of Aceclofenac + Paracetamol (13.75\%). Diclofenac (45.90\%) and Aceclofenac (15.96\%) were mostly prescribed. The study concluded that, prescription of NSAIDs was found to be rational. Education program, counselling program, alertness of community pharmacy regarding OTC drugs can be helpful to minimize harmful effect of the drug to patients [9].

\section{Methodology}

Study design: This study is a prospective observational study.

Study period: The study was conducted for a period of 6 months in the year 2018 .

\section{Study criteria}

Inclusion criteria:

- $\quad$ Male and female patients above 18 years of age.

- All patients prescribed with NSAIDs in general medicine, orthopedic, surgical inpatient departments.

Exclusion criteria:

- Patients below 18 years old.

- $\quad$ Pregnant and lactating women.

- $\quad$ Prescriptions not including NSAIDs.

Source of data: Patient's case sheet.

Data collection

- A suitable data collection form was designed for use in the study. The following data were collected from all the enrolled patients in the study.

- $\quad$ Patients demographic details.

- Indications.

- $\quad$ Patient's treatment chart.

Method of data collection

Data was collected from the patient's case sheets in the inpatients departments of surgical, orthopedic and general medical wards.

The above collected data was entered in to Microsoft excel.

\section{Study procedure}

The prospective observational study was carried out in orthopedic, surgical and general medicine inpatient departments.

After obtaining requisite permission, prescriptions will be copied on random basis to minimize bias.
The information such as patient name, age, co-morbidities, indications and all the drugs prescribed and their doses, dosage forms, route of administration, frequency, and category of the drug was recorded and analyzed.

Data was collected in a suitably designed data collection form

From the above data total number of NSAIDs prescribed and total number of drugs prescribed are analyzed.

Drug interactions severity was assessed by the sources Micromedex and MEDSCAPE drug interaction checker.

Collected data was entered into suitable statistical program and data was analyzed.

Statistical analysis

The collected data has been entered in to Microsoft excel obtained from sheet and the variables as percentage calculations were estimated. Graphs and charts were the data in Microsoft excel sheet. Mean and standard deviation was calculated by Graph Pad Prism.

\section{Results and Discussion}

Our study included 260 patients of which 133 (51.15\%) and 127 (48.85\%) were males and females respectively (Table 1).

\begin{tabular}{|l|c|c|}
\hline \multicolumn{1}{|c|}{ Gender } & Total No. of subjects & Percentage (\%) \\
\hline Male & 133 & 51.15 \\
\hline Female & 127 & 48.85 \\
\hline Total & 260 & 100 \\
\hline
\end{tabular}

Table 1

Age and gender wise distribution

The study population distributed within age group of 21- 30 was $13.46 \%, 31$ - 40 was $9.62 \%, 41$ - 50 was $25.77 \%$, 51 - 60 was $32.69 \%, 61-70$ was $12.69 \%$, and $71-80$ was $5.77 \%$. Mean \pm SD (AGE) was found to be $49.75 \pm 13.72$.

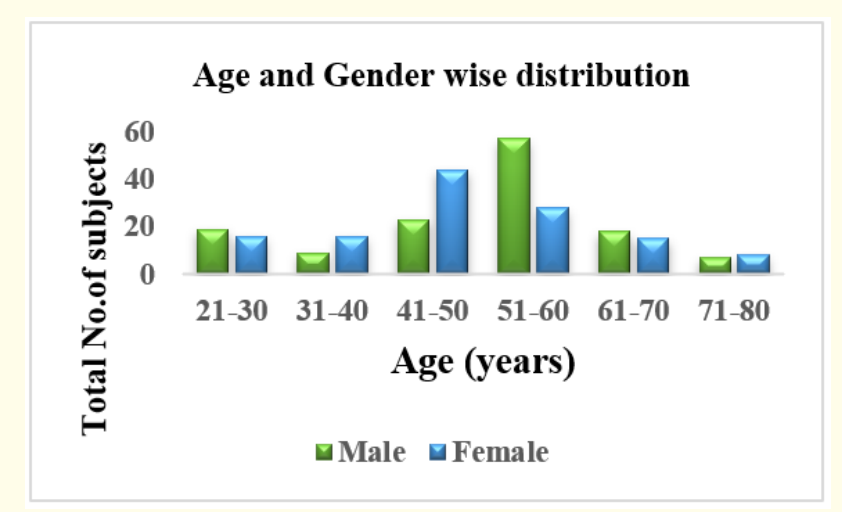

Figure 1

Clinical indications for which NSAIDs were prescribed

The commonest clinical indication for prescribing NSAIDs was Lower backache 36 (13.85\%) followed by fracture 28 (10.77\%), 
Musculo-skeletal pain 27 (10.39\%), OA 27 (10.39\%), RA 19 (7.31\%), Trauma and Abdominal pain were 18 (6.92\%), fever 17 (6.54\%), spondylosis 15 (5.77\%) and others 41 (15.77\%).

\begin{tabular}{|c|c|c|}
\hline Clinical indications & Total & Percentage (\%) \\
\hline Lower backache & 36 & 13.85 \\
\hline Musculo-skeletal pain & 27 & 10.39 \\
\hline Fracture & 28 & 10.77 \\
\hline Osteoarthritis & 27 & 10.39 \\
\hline Rheumatoid arthritis & 19 & 7.31 \\
\hline Trauma & 18 & 6.92 \\
\hline Fever & 17 & 6.54 \\
\hline Abdominal pain & 18 & 6.92 \\
\hline Spondylosis & 15 & 5.77 \\
\hline Others & 41 & 15.77 \\
\hline
\end{tabular}

Table 2

Frequency of NSAIDs prescribed

Percentage of prescribing frequency of NSAIDs was more in diclofenac 157 (42.32\%) followed by aceclofenac 76 (20.48\%), paracetamol 60 (16.17\%), nimesulide 17 (4.59\%), mefenamic acid 16 (4.32\%), ibuprofen 12 (3.23\%), aspirin 10 (2.69\%), naproxen 9 (2.42\%), etodolac 8 (2.16\%) indomethacin $6(1.62 \%)$

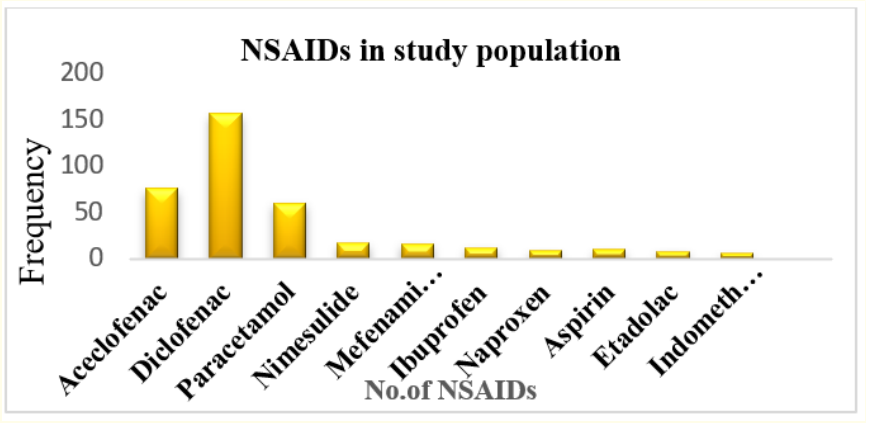

Figure 2

\section{Prescribing patterns of NSAIDs}

Prescribing patterns of NSAIDs among all the 260 prescriptions were divided according into their brand name and generic name. The drugs that are prescribed in brand name were found to be $(73.86 \%)$ are 273 in number, generic name $(26.14 \%)$ are in 97 in number.

Prescribing formulation of NSAIDs

Among the study sample size, the total number of injections prescribed was found to be $35.58 \%$ and tablets was $64.16 \%$, of NSAIDs that are prescribed.

Frequency of NSAIDs prescribed

The frequency of prescribing 371 NSAIDs to the 260 subjects was found in three frequency distribution parameters once in day (OD) $21.29 \%$, twice daily (BD) $70.08 \%$ and the NSAIDs prescribed thrice in day (TID) $8.63 \%$.

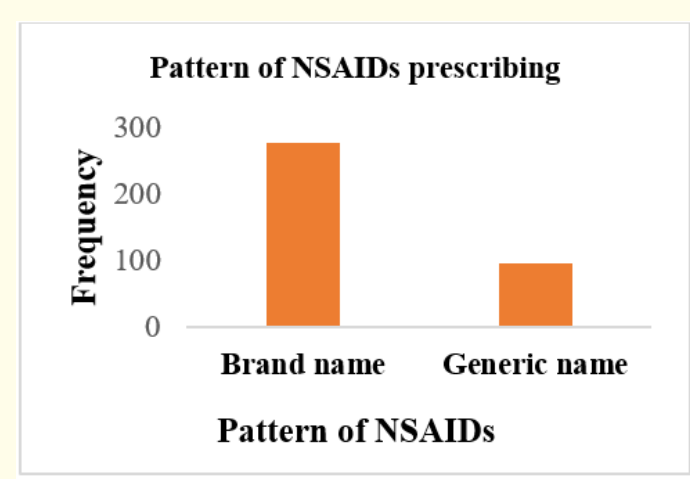

Figure 3

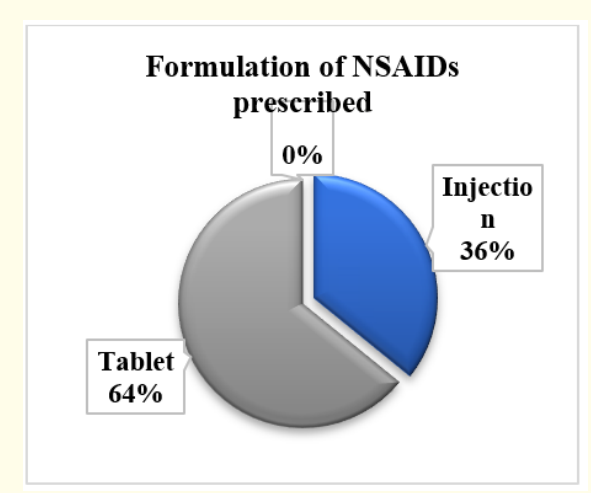

Figure 4

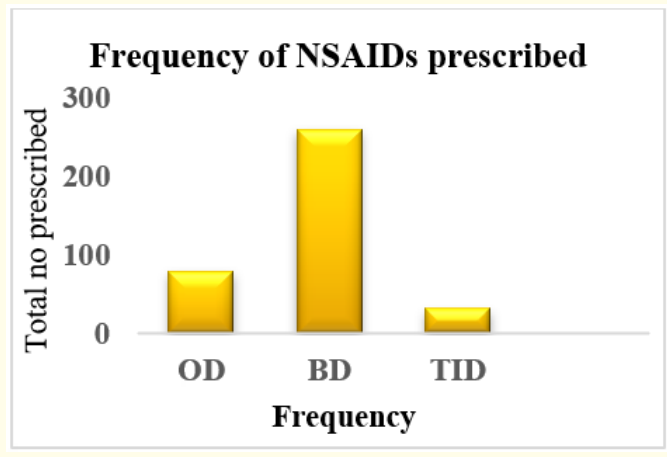

Figure 5

Route of administration of NSAIDs

Oral route $(65.69 \%)$ was the most preferred route of administration of NSAIDs comprising of 240 and second preferred was systemic route of administration accounting for IM (33.69\%) of 125 and intravenous (IV)was observed $1.62 \%$ of 6 in number

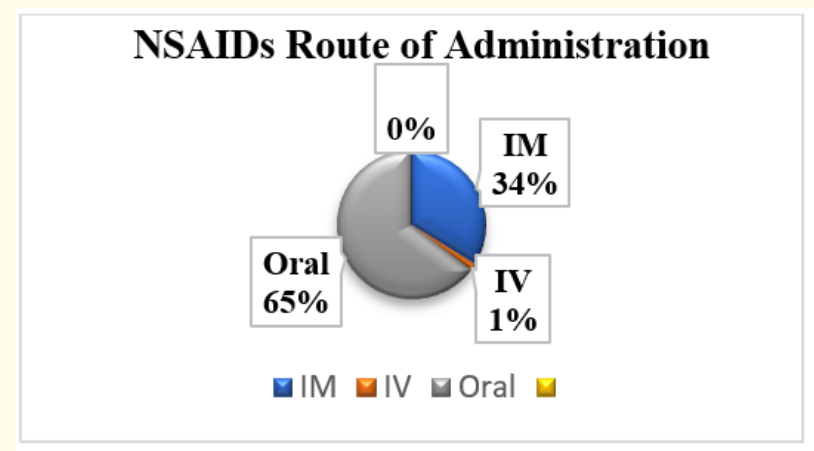

Figure 6 


\section{No of NSAIDs per prescription}

The average number of NSAIDs was $1.43 \pm 0.56$. One NSAID per prescription (159) was observed in $61.15 \%$ and two NSAIDs per prescription (92) as the second most in $35.38 \%$ of patients, three NSAIDs were found in only few prescriptions (9) accounting for $3.46 \%$.

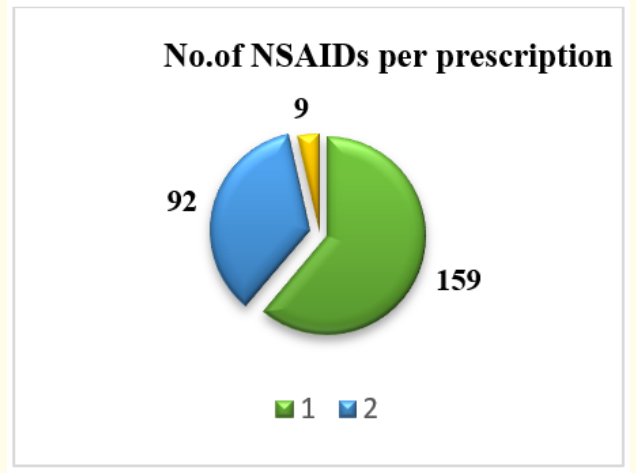

Figure 7

\section{GPAs prescribed with NSAIDs}

Gastroprotective agents are used in $64.70 \%$ of patients prescribed with NSAIDs mostly pantoprazole $56.66 \%$ followed by ranitidine $21.67 \%$, omeprazole $19.16 \%$ and famotidine was the least prescribed GPAs in $2.6 \%$ subjects.

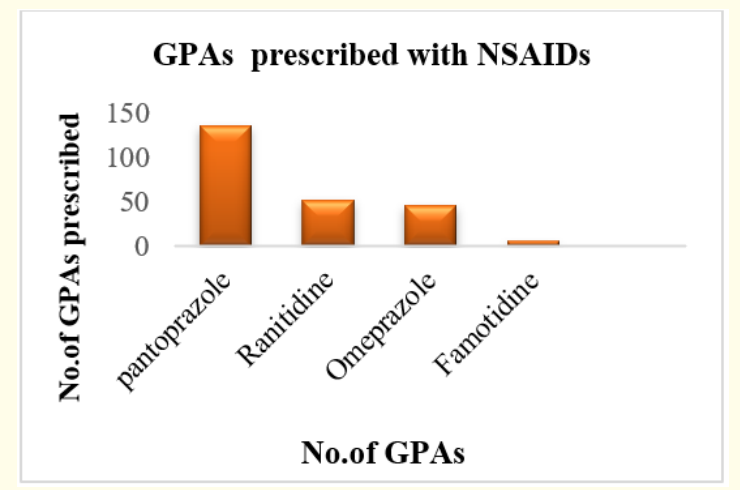

Figure 8

\section{No. of GPAs prescribed}

The study groups were stratified based on drugs prescribed to reduce NSAID induced GI risk observed in 240 patients. $75.83 \%$ of patients were prescribed with proton pump inhibitor and the rest $24.17 \%$ were on $\mathrm{H}_{2}$ receptor antagonist

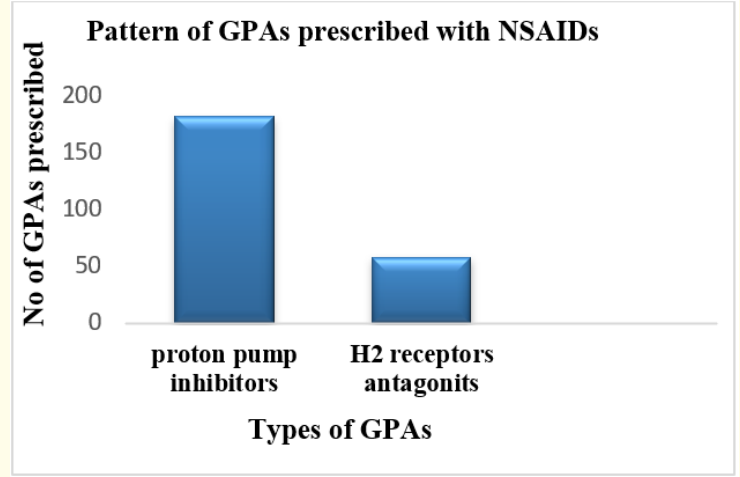

Figure 9
Severity drug-drug interactions

The severity assessment of drug-drug interactions of prescribing patterns of NSAIDs was grouped into three different sets, major drug interactions $(10.46 \%)$ was found to be 25 , moderate $(74.06 \%)$ was found to be 177 and minor $(15.48 \%)$ was found to be 37 .

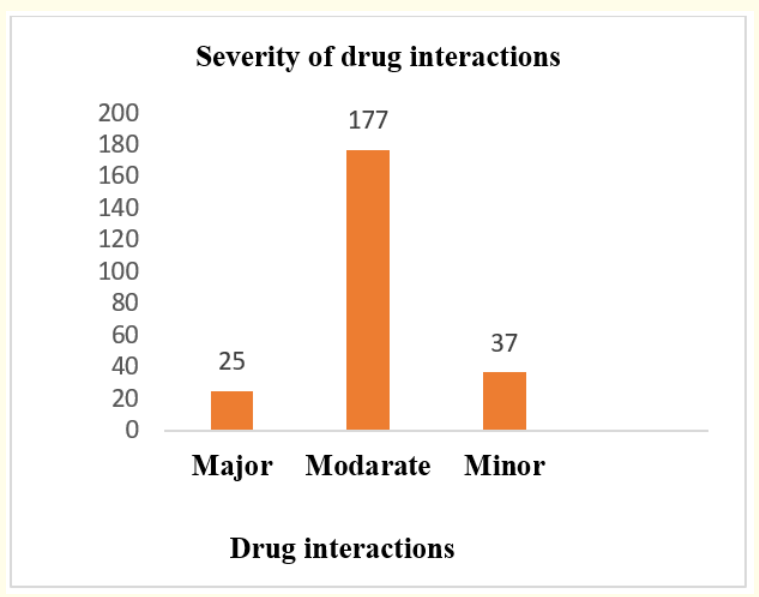

Figure 10

\begin{tabular}{|c|c|c|}
\hline Type of Severity & Number & Percentage \\
\hline Moderate & 177 & 74.06 \\
\hline Minor & 37 & 15.48 \\
\hline Total & 239 & 100 \\
\hline MeanSD & 1.961 .41 & - \\
\hline
\end{tabular}

Table 3

Drugs co-prescribed with NSAIDs

The drugs (864) they are co-prescribed with NSAIDs were mostly Gastroprotective agents (GPAs) among the other drugs that are prescribed in $6.25 \%$ (240), the second mostly co-prescribed were observed to be antibiotics $20.37 \%$ (176), antihypertensives 13.07\% (29), anti-emetics 3.93\% (34), anti-cholinergics 2.08\% (18), statins $1.73 \%$ (15) and the other drugs of $16.43 \%$ (142).

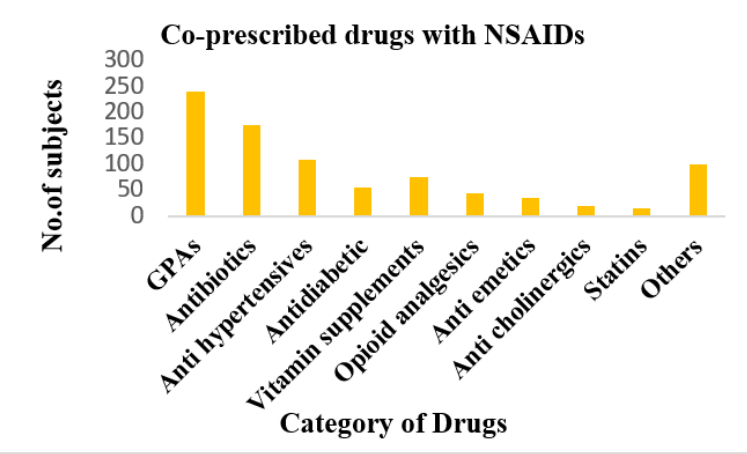

Figure 11

\section{Conclusion}

Based on the obtained results we conclude that the monotherapy with single NSAID was preferred mode of therapy via parenteral or oral therapy and GPA's should be co-prescribed for prevention from complications and there is a need to implement continuous 
monitoring of the drug interactions is to be prioritized to prevent adverse drug reactions which are major concern of drug interaction effects with the NSAID's.

\section{Bibliography}

1. Pincus T., et al. "Preference for non-steroidal anti-inflammatory drugs versus acetaminophen and concomitant use of both types of drugs in patients with osteoarthritis". Journal of Rheumatology 27.4 (2000): 1020-1027.

2. Rang HP., et al. "Anti-inflammatory and immunosuppressant drug". Laurance H, Barbara S. Pharmacology. $5^{\text {th }}$ edition. London. Churchill living stone (2003): 244-260.

3. Stuart J and Warden PT. "Prophylactic Use of NSAIDs by Athletes: A Risk/Benefit Assessment". Physician and Sports Medicine 38.1 (2010): 132-138.

4. Potthast H., et al. "Biowaiver monographs for immediate release solid oral dosage forms: ibuprofen". Journal of Pharmaceutical Sciences 94.10 (2005): 2121-2131.

5. John W. Daily-Pharmaceutical industry, Encyclopedia Britanica.

6. Johnson AG., et al. "Adverse Drug Interactions with Nonsteroidal Anti-Inflammatory Drugs (NSAIDs)". Drug-Safety 8.2 (1993): 99-127.

7. Anita P Antappan. "Prescription pattern of NSAIDS and the prevalence of NSAID-induced gastrointestinal risk factors of orthopaedic patient". Indian Journal of Pharmaceutical and Biological Research 5.3 (2017): 17-25.

8. Humaira Farheen., et al. "Prescription pattern of non-steroidal anti-inflammatory drugs in patients with acute musculoskeletal pain". International Journal of Basic and Clinical Pharmacology 5.6 (2016): 2504-2508.

9. S Kumar., et al. "Evaluation of prescribing pattern of NSAIDs in south Indian teaching hospital". Journal of Chitwan Medical College 6.18 (2016): 54-58.

\section{Assets from publication with us}

- Prompt Acknowledgement after receiving the article

- Thorough Double blinded peer review

- Rapid Publication

- Issue of Publication Certificate

- High visibility of your Published work

Website: https://www.actascientific.com/

Submit Article: https://www.actascientific.com/submission.php Email us: editor@actascientific.com

Contact us: +919182824667 